\title{
Hereditary angioedema type III (estrogen-dependent) report of three cases and literature review*
}

\author{
Angioedema hereditário tipo III (estrógeno-dependente): relato de três casos \\ e revisão da literatura
}

\author{
Amanda Rodrigues Miranda ${ }^{1}$ \\ Dominique Vilarinho Sabbag ${ }^{1}$ \\ Patrícia Karla de Souza ${ }^{4}$
}

\author{
Ana Paula Fusel de $\mathrm{Ue}^{2}$ \\ Wellington de Jesus Furlani ${ }^{3}$ \\ Osmar Rotta ${ }^{5}$
}

\begin{abstract}
In this article, three cases of hereditary angioedema (HAE) type III (estrogen-dependent or with normal C1 inhibitor) are reported. The HAE was initially described in women of the same family in association with high-leveled estrogenic conditions such as the use of oral contraceptives and pregnancy. There is no change in the $\mathrm{C} 1$ inhibitor as happens in other types of hereditary angioedema, and mutations are observed in the encoding gene of the XII factor of coagulation in several patients. The current diagnosis is mainly clinical and treatment consists in the suspension of the triggering factors and control of acute symptoms. A brief review of physiopathology, clinical features, genetic alterations and treatment are also presented.
\end{abstract}

Keywords: Angioedemas, hereditary; Estrogens; Hereditary angioedema type III; Therapeutics

Resumo: Neste artigo são relatados três casos de angioedema hereditário do tipo III (estrógeno-dependente ou com inibidor de C1 normal), que foi inicialmente descrito em mulheres da mesma família, em associação com condições de alto nível estrogênico, como uso de anticoncepcionais orais e gravidez. Não há alteração do inibidor de C1, como acontece nos outros tipos de angioedema hereditário, e são observadas mutações no gene codificador do fator XII da coagulação em várias pacientes. O diagnóstico atualmente é eminentemente clínico e o tratamento consiste na suspensão dos fatores desencadeantes e controle dos sintomas agudos. Também é apresentada breve revisão da fisiopatogenia, quadro clínico, alterações genéticas e tratamento.

Palavras-chave: Angioedemas hereditários; Angioedema hereditário tipo III; Estrogênios; Terapêutica

Received on 16.04.2012.

Approved by the Advisory Board and accepted for publication on 16.08.2012

Study carried out at the Department of Dermatology, School of Medicine - Federal University of São Paulo (EPM-UNIFESP) - São Paulo (SP), Brazil. Financial Support: None

Conflict of Interest: None

Dermatologist. Medical Residency in Dermatology by the Federal University of São Paulo (EPM-UNIFESP). Collaborator's Medical Group of Environmental Immuno Dermatosis Department of Dermatology, Federal University of São Paulo (EPM-UNIFESP) - Sao Paulo (SP), Brazil.

Dermatologist. Master of Dermatology by the Federal University of São Paulo (EPM-UNIFESP) - São Paulo (SP), Brazil.

Dermatologist. Medical Residency in Dermatology by the Federal University of São Paulo (EPM-UNIFESP). Collaborator's Medical Group of Environmental Immuno Dermatosis Department of Dermatology, Federal University of São Paulo (EPM-UNIFESP) - Sao Paulo (SP), Brazil.

4 Dermatologist. Master in dermatology by the Federal University of São Paulo (EPM-UNIFESP) - São Paulo (SP), Brazil. Medical contributor and coordinator of the Group of Environmental Immuno Dermatosis Department of Dermatology, School of Medicine - Federal University of São Paulo (EPM-UNIFESP) São Paulo (SP), Brazil.

Associate Professor, Department of Dermatology, Federal University of São Paulo (EPM-UNIFESP). - Lecturer responsible for Group of Environmental Immuno Dermatosis Department of Dermatology, School of Medicine - Federal University of São Paulo (EPM-UNIFESP) - São Paulo (SP), Brazil. 


\section{INTRODUCTION}

Hereditary angioedema (HAE) is a rare genetic disorder characterized by recurrent episodes of swelling of the skin and / or mucous, which can also affect the gastrointestinal tract and upper airways in a severe way. ${ }^{1}$ The crisis does not respond to antihistamines, corticosteroids or adrenaline and usually disappear spontaneously within $12-72$ hours. There is a mutation in the gene that encodes the $\mathrm{C} 1$ inhibitor of the complement factor (INHC1), inducing a reduction in its synthesis (type I HAE) or the formation of a dysfunctional protein (type II HAE). In 2000, a new subtype of HAE was described, which is clinically indistinguishable from the others, predominantly in women, in which the INHC1 is normal. ${ }^{2}$ The new disorder was called hereditary angioedema type III, estrogen-dependent hereditary angioedema or hereditary angioedema with normal $\mathrm{C} 1$ activity (type III HAE). There is a verifiable association with this type of hereditary angioedema and situations where increased levels of estrogen occur such as the use of oral contraceptives and pregnancy, which are recognised crises factors. ${ }^{2-4}$ The objective of this article is to describe the clinical and laboratory findings of three cases of this new type of HAE as well as briefly reviewing existing literature on the physiopathology, clinical features, genetic alterations, diagnosis and treatment.

\section{REPORT OF THE CASES}

1. Female patient, 35 years old, married, doctor, reported crisis of intense facial swelling for nine years, always attacking the lips. At the beginning the crisis were light and sporadic, but over time the crises were more intense, occurring at approximate two month intervals with a duration of at least two days. The crisis incapacitated the patient from her socio-labor activities due to alteration in facial esthetics. Abdominal pain or respiratory alterations were never symptoms during the attacks. She reported having initiated the use of oral contraceptives for about nine years with no pause. She never got pregnant. There was no known history of angioedema in her family. The crises were not associated with the intake of any medication. The initial diagnostic hypotheses were made of common angioedema and hereditary angioedema (HAE). During the investigation, an idiopathic thrombocitosis was discovered and started being monitored along with a hematologist. The general tests, except for an increase in platelet levels, were normal, as were the $\mathrm{C} 4, \mathrm{C} 1 \mathrm{q}$ and $\mathrm{C} 1$ inhibitor (Chart 1). The inhibitor had been asked previously and always appeared normal. It was requested a discontinuation of oral contraceptives for possibly dealing with a case of HAE type III but also by thrombocito- sis. After stopping the medication, the patient had no more angioedema crisis. She has been monitored for three years.

2. Female patient, 35 years, single, biomedical researcher, with a 12 years history of recurrent episodes of severe edema on the upper lip and face. Initially the attacks occurred twice a year however last year these became more serious, occurred fortnightly and with a duration of 4 to 5 days, including once requiring hospitalization in the Intensive Therapy Unit (Figures 1 and 2). The patient related the crisis to emotional stress and also reported a worsening of symptoms during menstruation. She also never became pregnant. The patient had been taking oral contraceptives for 12 years, but never associated it with the crisis of angioedema. She had previously used a large number of antihistamines, corticosteroids and adrenaline, without improvement. Her mother had similar episodes of angioedema for 28 years, but in the last eight years she did not have more attacks. Diagnostic hypotheses of common and hereditary angioedema were made and tests were requested for the diagnosis, during the inter-crisis and crisis period (Chart 1).

Since there was no change in the INHC1, it was thought to be a possible case of type III HAE, resulting in the suspension of the oral contraceptive. The patient has subsequently been free of attacks, a period of 30 months.

3. Female patient, 26 years, single, student, with a history of the appearance two years ago of recurrent swellings on her face and in various other locations on

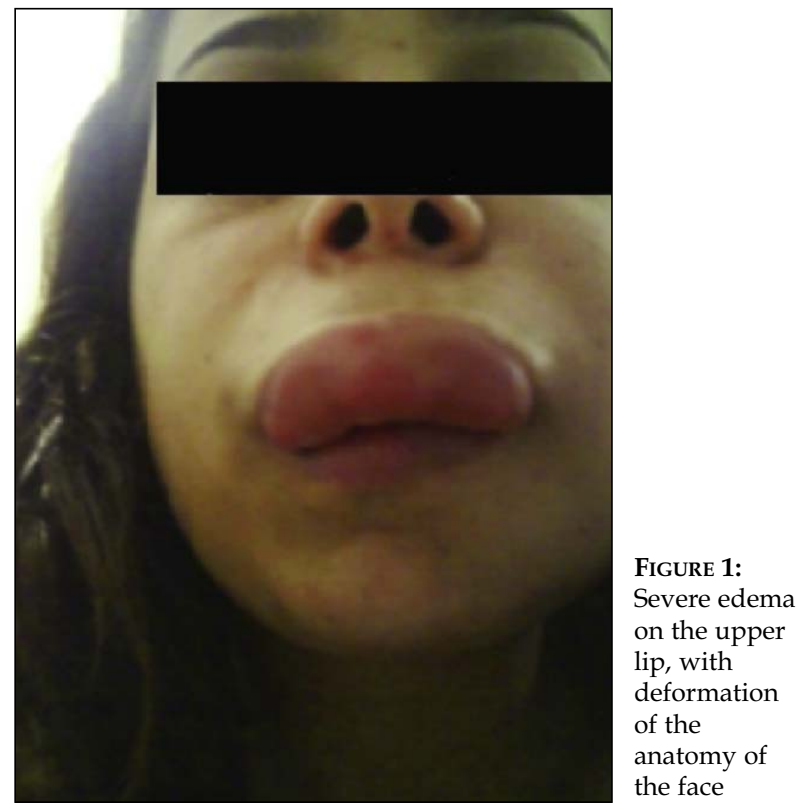




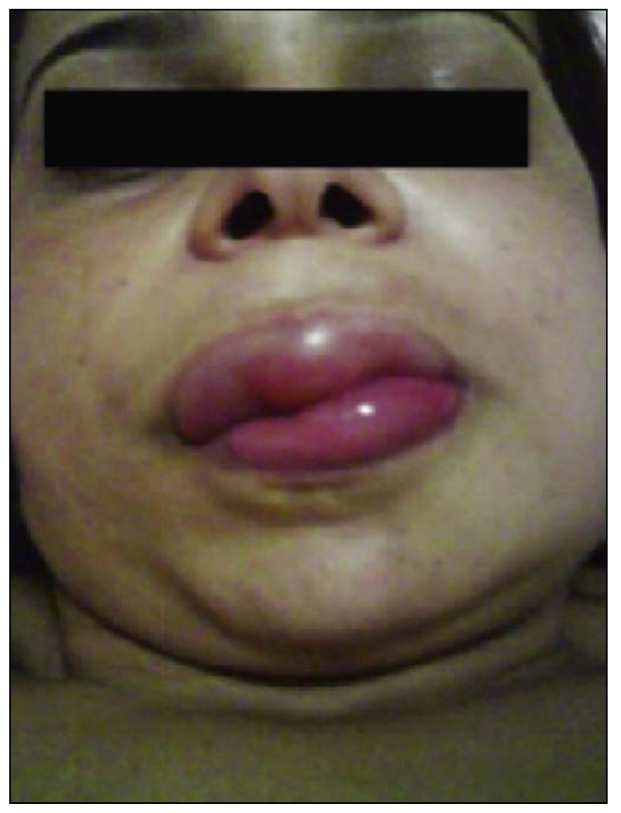

FIGURE 2: Edema of the upper and lower lips and face

her body. She reported that the crisis were initially sparse however last year the frequency increased, occurring once or twice a month and preventing her normal activities. During these two years she had intense abdominal pain twice, along with facial swelling. The crisis did not respond to therapy with antihistamines and / or corticosteroids. She had used oral contraceptives for 10 years, and eventually other drugs, which she did not relate to episodes of facial swelling. The patient never fell pregnant. There was no family history of angioedema. The initial diagnostic hypotheses were made of common angioedema and hereditary angioedema. The examinations were normal between and during the crisis, including $\mathrm{C} 1$ and $\mathrm{C} 4$ inhibitor (Chart 1 ). Since there was no change in the inhibitor, the possibility of hereditary angioedema type III was considered. We opted for the suspension of oral contraceptives and she experienced no further attacks, being monitored for 21 months.

\section{DISCUSSION AND LITERATURE REVIEW}

Angioedema is clinically characterized by sudden swelling of the skin and / or mucous, including respiratory and gastrointestinal tracts, with limited duration of 2 to 3 days, not itchy, but with pain and variable burning sensations. ${ }^{1}$ In many patients, it is associated with crisis of urticaria, taking part in this case of the clinical picture on the same disease. However, if the angioedema occurs alone, it's classified as a separate entity and is called angioedema without wheals, which may be acquired or hereditary. ${ }^{1}$
Hereditary angioedema (HAE) is a rare dominant Mendelian gene inheritance, affecting approximately 1:50,000 people. 1 It is currently classified into three types (I, II and III), according to the deficiency or absence of $\mathrm{C} 1$ inhibitor (INHC1). In the first two types there is INHC1 deficiency, quantitative in HAE type I and qualitative in type II. In the type III the deficiency of INHC1 does not occur. ${ }^{2}$

The INHC1 is a regulatory protease of the classical pathway of the complement system whose function is to inhibit the proteolytic activation of $\mathrm{C} 2$ and $\mathrm{C} 4$, coagulation factor XII (Hagemann factor) and the production of kallikrein, plasmin and bradykinin. Deficiency in INHC1 causes uncontrolled inflammation consequent to the overproduction and accumulation of bradykinin, the major mediator of angioedema. ${ }^{3}$

The crises of HAE can be triggered by trauma, pressure, emotional stress and the use of medications, especially inhibitors of angiotensin-converting enzyme (ACE) and estrogens, which may induce and / or exacerbate quiescent disease in all types of HAE. 3 The crises of HAE are uncomfortable for the patient, but doesn't offer risk of death, except when they involve the airways, which could result in asphyxiation. $^{3}$ All three types of HAE have the same incidence of asphyxia and death.

Many patients also present bowel wall edema during the crises, which clinically results in episodes of severe and debilitating abdominal pain, sometimes the only symptom of HAE. Vomiting and alteration of the intestinal pace may also be exhibited, symptoms which often mimic an acute abdomen. ${ }^{3}$

In relation to pregnancy, patients with $\mathrm{HAE}$ usually improve, especially from the second quarter. The trauma of delivery does not precipitate the crisis, but these may recur after the first week of the puerperium. $^{3}$

The HAE type III was first reported in 2000 by Bork et al, affecting women without qualitative or quantitative INHC1 alteration. ${ }^{2}$ The crises are related to the use of estrogen and during pregnancy. In this article, we described three cases of patients with hereditary angioedema type III. All of them had a clinical feature of angioedema without wheals, with frequent disabling episodes affecting their social and laborative lives, involving mainly the face. Dosages of INHC1 and C4 were normal between and during the crisis (Chart 1).

It is known that estrogen has a role not yet fully understood in the crisis of HAE type III. In many cases, the estrogen initiated and / or exacerbated the crisis of angioedema, as with the patients described in this article. ${ }^{5}$ Binkley and Davis created the term estrogendependent after observing angioedema conditions in women with high-leveled conditions of estrogen. ${ }^{6}$ 


\begin{tabular}{|lccc|}
\hline \multicolumn{3}{|c|}{ CHART 1: Clinical features and laboratorial examinations of the patients } & 3 \\
\hline Initial age & $\mathbf{1}$ & 2 & 24 \\
Association with contraceptive & 26 & 23 & Yes \\
Association with pregnancy & Yes & Yes & - \\
Affected family members & - & - & No \\
Episodes of laryngeal edema & No & Yes \\
Response to corticosteroids and / or antihistamines & No & Yo & No \\
Hemogram & Thrombocytosis & Normal & Normal \\
Quantitative and Qualitative INHC1 & Normal & Normal & Normal \\
C4 & Normal & Normal & Normal \\
\hline
\end{tabular}

They also proposed a mutation in the androgen locus of the gene that encodes the INHC1. Elevated estrogen levels are associated with increased levels of factor XII that, when activated, converts prekallikrein to kallikrein, and consequently produces a greater amount of bradykinin. ${ }^{7}$ Besides this, high levels of estrogen during pregnancy or with the use of oral contraceptives are associated with a reduction of INHC1. ${ }^{7}$

The inheritance pattern of HAE type III has been the subject of numerous studies and a source of discussion since the first reported cases. Initially, Bork et al suggested a dominant inheritance X-linked, because all affected patients were female. ${ }^{4}$ Binkley and Davis reported an Italian family with HAE type III that presented a dominant gene whose males were asymptomatic carriers of the anomaly.,7 Bork et al also reported the occurrence of the disease in a family in which three patients were male, suggesting a gene inheritance indeed, but not necessarily X-linked. ${ }^{8}$ In this case, there could be another mutation, as is observed in other types of HAE, without the existence of cases previously reported in the same family. In 2006 Dewald G et al and Cichon et al identified two mutations in the FXII gene (decoder of the Hagemann factor) that would lead to a substitution of threonine to lysine (Thr309Lys) and another that would replace the threonine to arginine (Thr309Arg). ${ }^{9,10}$ However, not all families of patients with HAE type III would have these mutations. Besides these, several other mutations have been described over the past year, indicating a genetic polymorphism that contributes to phenotypic diversity of HAE type III. ${ }^{710-14}$
There are reports of non-family cases, sporadic, that could present new genetic mutations, different to those already described so far and still unknown. ${ }^{10}$ Of the three patients described in this article, only one presented a known family history of angioedema (mother). Genetic tests that could classify patients with a genetic alteration were not performed due to the difficulty of such tests in our facilities.

Recently, Bork proposed a new classification of HAE, according to the latest genetic findings. According to this new classification, there were three types of HAE:

(a) with a genetic deficiency of INHC1 (HAE types I and II);

(b) with normal INHC1 (HAE type III) including those with two known mutations of the gene factor XII (FXII-HAE) and those of unknown genetic cause (HAE-unknown). ${ }^{4}$

The HAE attacks begin during childhood and worsen at puberty but can occur at any age. The onset of symptoms in adulthood is significantly higher in patients with HAE type III..$^{13}$

Symptoms of HAE type III are similar to other types of HAE: recurrent skin swelling, abdominal pain attacks, swelling of the tongue and pharynx. There are no associated wheals. ${ }^{13}$ The main clinical and laboratorial differences with the HAE with INCH1 deficiency (types I and II) and normal INCH1 (type III) are in chart 2.

Bork suggested that the face would be the site most affected in these patients, especially the lips. ${ }^{12}$ It is observed that the clinical manifestations of HAE 
CHART 2: Some clinical characteristics that distinguish normal HAE with INHC1 from HAE with reduced INHC1 - Bork modified, 2010

Patients have normal INHC1 activity

It mainly affects women

The incidence is lower in children aged under 10. The clinical symptoms begin in adulthood in most patients

There are more remission breaks in the course of the disease

Facial swelling, especially of the lips, is relatively more frequent

The tongue is considerably more affected

Many patients present only cutaneous angioedema and tongue swelling

Abdominal attacks are less frequent

Asphyxia can be preceded and caused by swelling of the tongue

There is no erythema marginatum, which is characteristic of HAE due to INHC1 deficiency

type III are highly variable and it is believed that the penetration of the disease is low, since there are reports of symptoms emerging in seemingly asymptomatic female carriers of the genetic changes in the seventh decade of their lives. ${ }^{13}$ In addition, there are reports of symptomatic patients with normal and / or low levels of estrogens, besides the manifestation of the disease in men. ${ }^{10}$

All patients described in this article began the crises in adulthood, affecting mainly the face, with lip swelling and eventually associated swelling of the tongue and larynx. Patient 1 still had abdominal pain associated with skin condition.

Laboratory tests are required for the diagnosis of HAE when there is a clinical suspicion and / or family history of angioedema. The serum $\mathrm{C} 4$ and INHC1 dosages are recommended (quantitative and qualitative). The C4 and INHC1 should also be evaluated in crises when the results are normal. There is no indication of dosing $\mathrm{CH} 50$ or $\mathrm{C} 3 .{ }^{14}$ Figure 3 shows the algorithm diagnosis of HAE. If both the $\mathrm{C} 4$ and the quantitative INCH1 are low, then the diagnosis is compatible with Type I HAE. If the C4 is below normal and the quantitative INCH1 is normal, it is suggested the dosage of qualitative INHC1; if it's low, the diagnosis is compatible with HAE type II. All tests should be repeated on another occasion to confirm the diagnosis. ${ }^{14}$ If both the $\mathrm{C} 4$ and the quantitative INCH1 are normal, types I and II can be excluded and the hypothesis of HAE type III should be considered. In this case, the repetition of the tests during the angioedema crisis is always recommended. ${ }^{14}$
In patients under 1 year old the laboratory tests are not reliable and should be repeated with greater age, because it may cause false positive results and / or false negative even when there are genetic alterations. ${ }^{14}$

The $\mathrm{C} 4$ and quantitative INHC1 dosages are routine examinations in large laboratories, but the qualitative assessment of $\mathrm{C} 1$, in our environment, is performed only in a few specialized laboratories.

So far the diagnosis of HAE type III is conducted by clinical criteria, therefore there are no laboratory tests to confirm it. ${ }^{10}$ In cases of suspected genetic mutation with the HAE and FXII, the diagnosis requires a confirmation of the mutation, reproducible only in research centers. In our patients, the absence of laboratory parameters, coupled with the clinical feature and immediate response to the removal of estrogen led to the diagnosis. ${ }^{10}$

The treatment of HAE consists of the management of the attacks and long-term prophylaxis. It is well recognized that corticosteroids, antihistamines and epinephrine are not useful. ${ }^{3,15}$

The therapeutic experience of this new type of HAE is limited because there are no well-controlled studies. ${ }^{10}$

Initially the use of estrogens (oral contraceptives and hormone replacement therapy) must be suspended, as high levels of this hormone are related to angioedema crisis.

In the acute phase, the following medications can be used: concentrated INCH1, fresh frozen plasma, ecallantide and icatibant. ${ }^{15}$ 


\section{Consider clinical features: angioedema without wheals, laryngeal edema, recurrent episodes of abdominal pain and vomiting, positive family history}

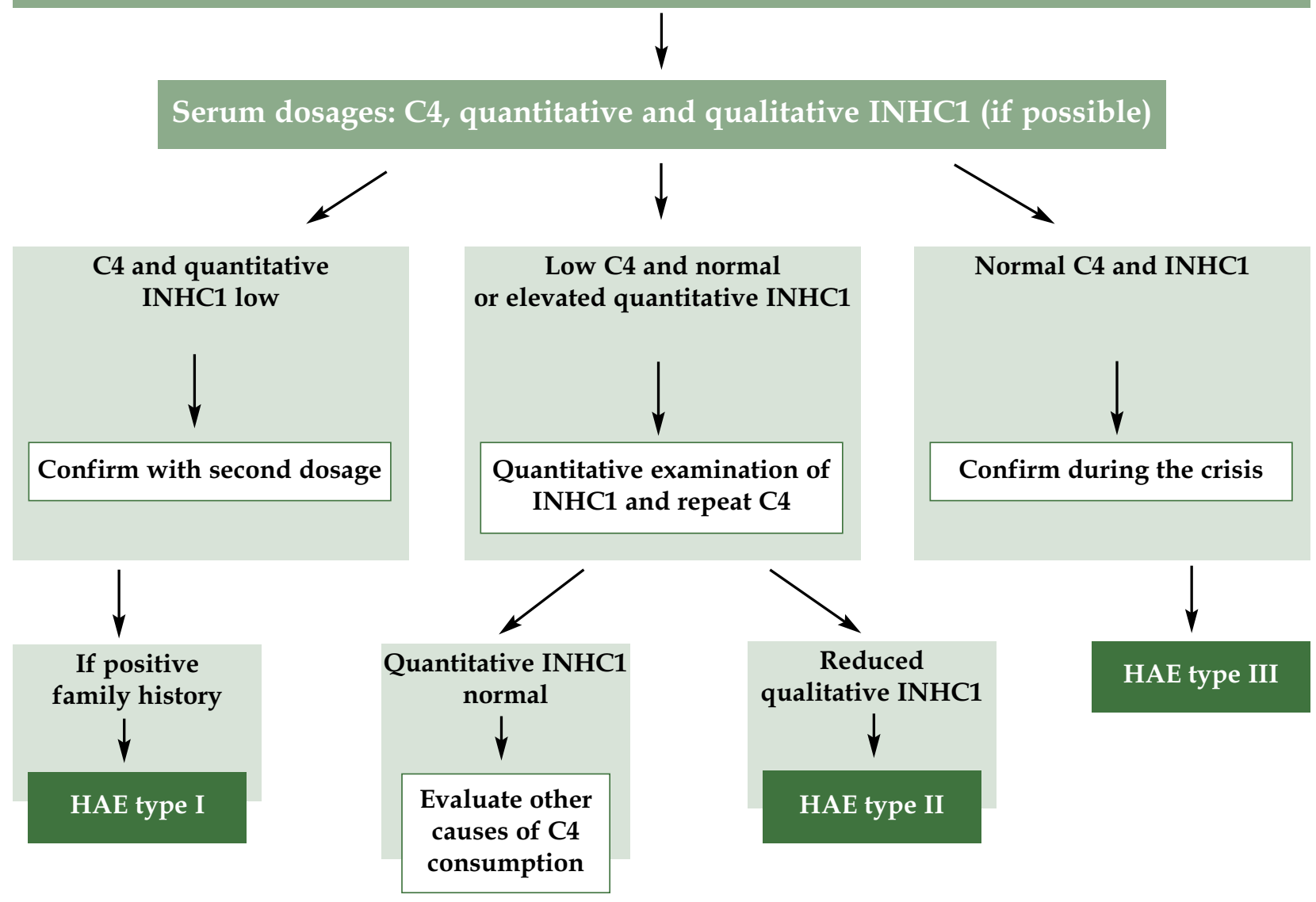

FIGURE 3: Algorithm of diagnosis of hereditary angioedema (HAE)

In a study of seven patients with estrogendependent HAE who received concentrated dose of INHC1 during the angioedema crisis, six reported moderate or significant improvement of symptoms. ${ }^{13}$

Fresh frozen plasma is effective in the acute phase of classical types of HAE. There is a theoretical basis for using it also in HAE type III, especially if the use of concentrated INCH1 is not possible. 10 However, there is no evidence in the literature to justify its usage.

The ecallantide is a potent and selective inhibitor of kallikrein which has been recently used successfully in the crises of the classical HAE. ${ }^{16}$ However, there are still no reports of its use for HAE type III. ${ }^{10}$

The icatibant, an antagonist of the bradykinin B2 receptor, has been shown to be effective in the treatment of episodes of HAE, including the estrogen- dependent HAE, with the resolution of symptoms within 2-3 hours. ${ }^{17}$

Prophylactic therapy consists in the use of attenuated androgens, antifibrinolytic agents and progesterone. The attenuated androgens are the most effective drugs and well tolerated because they increase the levels of INHC1 and reduce the frequency of crisis. ${ }^{3}$ Danazol is the most frequently used drug and can lead to remission of symptoms in patients with HAE- FXII. ${ }^{15}$ Adverse effects such as hepatotoxicity and virilization are uncommon. ${ }^{3}$ Tranexamic acid is an antibrinolitic agent used for prophylaxis of classical forms of HAE and acts preventing the activation of factor XII (by the anti-plasmin action). Cicardi et al reported the effectiveness of tranexamic acid in patients with idiopathic angioedema, in which many of these, by the clinical features, would present undiagnosed HAE type III. ${ }^{9}$ There are reports of its suc- 
cessful use in a patient with estrogen-dependent HAE. ${ }^{15}$ Its use is indicated in cases with persistent symptoms even after the suspension of estrogen. ${ }^{10}$ Attention should be paid to the higher incidence of thromboembolism during its use.

Pregnant women represent a problem because androgens and antifibrinolytic agents are contraindicated. ${ }^{3}$

Progesterone was used between 1 to 6 years in a study of eight patients with HAE FXII. Seven of them taked progesterone in the form of oral contraceptive and one pacient taked in the form of medroxyprogesterone injections. All remained attacks free during the treatment. ${ }^{13}$

To sum up, there are several treatment options aiming the control of crisis for patients with HAE estrogen-dependent, but none confirmed with controlled studies. Most important, as an initial measurement, is the suspension of exogenous estrogen (oral contraceptives or hormone replacement therapy). Currently, during crises, the best treatment seems to be the concentrated INCH1, not available in Brazil. 10
The three patients described in this article showed a total improvement of the crisis only with the suspension of oral contraceptives. They had previously used medications such as antihistamines, corticosteroids and adrenaline, without success. Since the condition remains in remission, it is not necessary to administer any prophylactic drugs.

In conclusion, the HAE type III or estrogendependent disease is recent and rare, with a diagnosis based on the clinical chart, family history and in many cases, association with estrogen. The three cases reported in this article demonstrate it is a disease with a relatively simple diagnosis and treatment, which often goes unnoticed in our daily clinical practice. This disease when recognized and correctly diagnosed leads to effective therapeutic measures instituting a vast improvement in the quality of life of patients, since it is commonly understood that angioedema causes great social and physical embarrassment. $\square$

\section{REFERENCES}

1. Kaplan AP, Greaves MW. Angioedema. J Am Acad Dermatol. 2005;53:373-88.

2. Bork K, Barnstedt SE, Koch P, Traupe H. Hereditary angioedema with normal C1inhibitor activity in women. Lancet. 2000;356:213-7.

3. Serrano C, Guilarte M, Tella R, Dalmau G, Bartra J, Gaig P, et al. Oestrogen dependent hereditary angio-oedema with normal $C 1$ inhibitor: description of six new cases and review of pathogenic mechanisms and treatment. Allergy. 2008;63: 735-41.

4. Bork K. Diagnosis and treatment of hereditary angioedema with normal C1 inhibitor. Allergy Asthma Clin Immunol. 2010; 6:15.

5. Frank MM, Durham MD. Hereditary angioedema. J Allergy Clin Immunol. 2008; 121:S398-401.

6. Binkley KE, Davis A. Clinical, biochemical, and genetic characterization of a novel estrogen-dependent inherited form of angioedema. J Allergy Clin Immunol. 2000;106:546-50.

7. Binkley KE. Factor XII mutations, estrogen-dependent inherited angioedema and related conditions. Allergy Asthma Clin Immunol. 2010;6:16.

8. Bork K, Gül D, Dewald G. Hereditary angio-oedema with normal $\mathrm{C} 1$ inhibitor in a family with affected women and men. Br J Dermatol. 2006;154:542-5.

9. Dewald G, Bork K. Missense mutations in the coagulation factor XII (Hageman factor) gene in hereditary angioedema with normal $\mathrm{C} 1$ inhibitor. Biochem Biophys Res Commun. 2006; 343:1286-9.

10. Cichon S, Martin L, Hennies HC, Müller F, Van Driessche K, Karpushova A, et al. Increased activity of coagulation factor XII (Hageman factor) causes hereditary angioedema type III. Am J Hum Genet. 2006;79:1098-104.

11. Cicardi M, Castelli R, Zingale LC, Agostoni A. Side effects of long-term prophylaxis with attenuated androgens in hereditary angioedema: comparison of treated and untreated patients. J Allergy Clin Immunol. 1997;99:194-6.

12. Bork K, Wulff K, Hardt J, Witzke G, Staubach P. Hereditary angioedema caused by missense mutations in the factor XII gene: clinical features, trigger factors, and therapy. J Allergy Clin Immunol. 2009;124:129-34.
13. Gompels MM, Lock RJ, Abinum M, Bethune CA, Davies C, Grattan C, et al. C1 inhibitor deficiency: consensus document. Clin Exp Immunol. 2005;139:379-94.

14. Bowen T, Cicardi M, Farkas H, Bork K, Longhurst HJ, Zuraw B, et al. 2010 International consensus algorithm for the diagnosis, therapy and management of hereditary angioedema. Allergy Asthma Clin Immunol. 2010;6:24.

15. Bork K, Gul D, Hardt J, Dewald G. Hereditary angioedema with normal $\mathrm{C} 1$ inhibitor: clinical symptoms and course. Am J Medicine. 2007;120:987-92.

16. Ladner R, Kent R, Ley A, Nixon A, Sexton D. Discovery of Ecallantide: a potent and selective inhibitor of plasma kallikrein. J Allergy Clin Immunol. 2007;119:S312.

17. Bouillet L, Boccon-Gibod I, Ponard D, Drouet C, Cesbron JY, Dumestre-Perard C, et al. Bradykinin receptor 2 antagonist (icatibant) for hereditary angioedema type III attacks. Ann Allergy Asthma Immunol. 2009;103:448.

\author{
MAILING ADDRESS: \\ Amanda Rodrigues Miranda \\ Rua 1125, 312, sala 201 - Setor Marista \\ 74175-090 - Goiânia - Goiás \\ Brazil \\ E-mail: contato@amderma.com.br
}

How to cite this article: Miranda AR, Ue APF, Sabbag DV, Furlani WJ, Souza PK, Rotta O. Hereditary angioedema type III (estrogen-dependent) report of three cases and literature review. An Bras Dermatol. 2013;88(4):578-84. 